
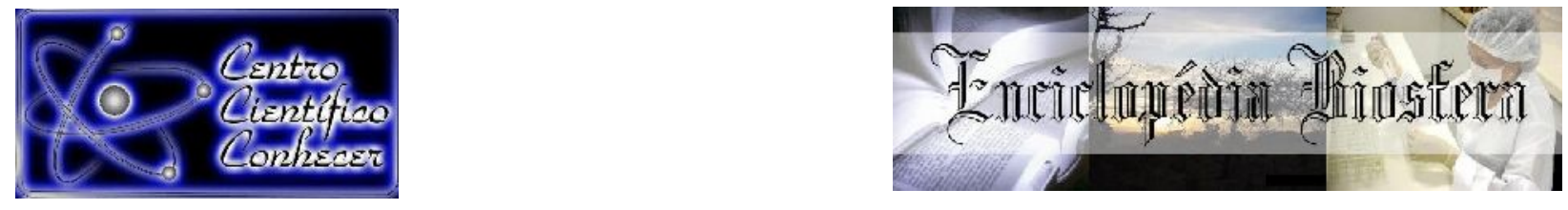

\title{
ANÁLISE QUALI-QUANTITATIVA DA ARBORIZACAO URBANA DA CIDADE DE ACRELÂNDIA - ACRE
}

$\underline{\text { Ivan de Oliveira' }}{ }^{1}$, Evandro José Linhares Ferreira², João Bosco Nogueira de Queiroz $^{3}$

1 Engenheiro Florestal, Instituto Nacional de Pesquisas da Amazônia-INPA, Rio Branco, Acre. (eng.ivandeoliveira@gmail.com)

2 Engenheiro Agrônomo, Pesquisador do Instituto Nacional de Pesquisas da Amazônia-INPA, Rio Branco, Acre.

${ }^{3}$ Gestor Ambiental, Instituto Nacional de Pesquisas da Amazônia-INPA, Rio Branco, Acre.

Recebido em: 22/09/2018 - Aprovado em: 23/11/2018 - Publicado em: 03/12/2018 DOl: 10.18677/EnciBio_2018B7

O cultivo de árvores em áreas urbanas pode proporcionar benefícios estéticos, sociais, econômicos e ecológicos aos habitantes das cidades. Entretanto, quando ele é feito sem planejamento adequado pode ocasionar numerosos problemas, especialmente nas estruturas urbanas adjacentes ao mesmo. Este estudo é uma avaliação quali-quantitativa da arborização urbana da cidade de Acrelândia, Acre. Foi realizado um censo e avaliação individual das condições fitossanitárias, estádio de crescimento e posição/condição de cultivo de todos os indivíduos arbóreos com DAP/DAC $\geq 10 \mathrm{~cm}$ nas 59 ruas da cidade. Foram encontradas 375 árvores pertencentes a 15 famílias botânicas, classificadas em 25 espécies. Ficus benjamina foi a espécie mais frequente, com $61,3 \%$ dos indivíduos encontrados. A quantidade de árvores $/ \mathrm{km}$ linear de calçada foi de 5,75, abaixo das 100 árvores $/ \mathrm{km}$ recomendadas pela SBA. Espécies oriundas de outras regiões representaram 92,8\% das árvores cultivadas. A maioria $(84,5 \%)$ das árvores era cultivada em calçadas, mas poucas interferiam na fiação elétrica e/ou iluminação pública. A poda era necessária em $36,8 \%$ das árvores avaliadas e troncos sem injúrias predominaram em $80,5 \%$ delas. O colo de $46,1 \%$ das árvores era pavimentado, e a maioria não apresentava espaço adequado. Os danos causados pelo sistema radicular foram mais frequentes em calçadas (42,7\%), mas $47,7 \%$ dos indivíduos avaliados não causavam danos. A fitossanidade era boa em $96 \%$ das árvores e a taxa de mortalidade foi de apenas 2,1\%. Conclui-se que a arborização em Acrelândia foi mal planejada e executada, e tanto a diversidade de espécies como a quantidade de árvores cultivadas $/ \mathrm{km}$ linear de calçada eram baixas.

PALAVRAS-CHAVE: Amazônia, Flora Urbana, Inventário florestal urbano. 


\title{
QUALI-QUANTITATIVE ANALYSIS OF URBAN TREATMENT OF THE CITY OF ACRELAND - ACRE
}

\begin{abstract}
The tree cultivation in urban areas can provide aesthetic, social, economic and ecological benefits to city inhabitants. However, when it is done without proper planning it can cause numerous problems, especially in the urban structures adjacent to it. This study is a qualitative and quantitative evaluation of the urban trees cultivated in the city of Acrelândia, Acre. A census and individual assessment of the phytosanitary conditions, growth stage and cultivation position / condition of all individual trees with $\mathrm{DBH} / \mathrm{ACD} \geq 10 \mathrm{~cm}$ was carried out in all of the city 59 streets. There were 375 trees belonging to 15 botanical families, classified in 25 species. Ficus benjamina was the most frequent species, with $61.3 \%$ of the individuals found. The number of trees per linear kilometer of sidewalk was 5.75, below the 100 trees / $\mathrm{km}$ recommended by the SBA. Species from other regions accounted for $92.8 \%$ of cultivated trees. Most (84.5\%) of the trees were cultivated on sidewalks, but few interfered with electrical wiring and / or street lighting. Pruning was necessary in $36.8 \%$ of the evaluated trees and trunks without injuries predominated in $80.5 \%$ of them. The neck region at the base of the trunk was paved in $46.1 \%$ of the trees, and most did not have adequate space. Damage caused by the root system was more frequent on sidewalks (42.7\%), but $47.7 \%$ of the individuals evaluated did not cause damage. Plant health was good in $96 \%$ of the trees and the mortality rate was only $2.1 \%$. It was concluded that tree planting in Acrelândia was poorly planned and executed, and both the diversity of species and the number of trees cultivated / linear $\mathrm{km}$ of sidewalk were low.
\end{abstract}

KEYWORDS: Urban forest inventory, Amazon, Urban flora.

\section{INTRODUÇÃO}

A arborização urbana incluiu todos os elementos vegetais de porte arbóreo, naturais ou cultivados, encontrados dentro do perímetro urbano de uma cidade (LACERDA et al., 2014), incluindo aqueles presentes em áreas públicas e privadas, em calçadas, praças, parques, margens de corpos de água e em jardins.

As árvores cultivadas em áreas urbanas inserem-se como elementos estruturadores do espaço urbano pelo fato de proporcionarem numerosos benefícios estéticos, sociais, econômicos e ecológicos que promovem a melhoria da qualidade ambiental e do bem estar dos habitantes das cidades (ZAMPRONI et al., 2018).

Objetivamente, o cultivo de árvores em áreas urbanas ajuda a minimizar o impacto ambiental causado pela expansão das cidades (FARIA et al., 2013; OLIVEIRA et al., 2013) e quando executado de forma correta, ele poderá proporcionar diversas vantagens para a população, com destaque para seu papel no controle de ruídos, da umidade atmosférica excessiva, na diminuição da velocidade dos ventos, na melhoria da qualidade do ar e no sombreamento que proporciona aos pedestres em vias públicas, parques e jardins.

Apesar da importância da arborização urbana, na maioria das cidades brasileiras ela tem sido implantada sem planejamento adequado (GOMES et al., 2016). O planejamento da implantação da arborização é indispensável, pois sua ausência pode ocasionar numerosos problemas (CRISPIM et al., 2014; OLIVEIRA et al., 2017). O plantio inadequado das árvores pode resultar, na medida em que elas 
crescem, em danos ao calçamento e muros adjacentes, às redes de esgoto, elétrica e de telefonia (SANTOS et al., 2013; SANTOS et al., 2015; SANTOS et al., 2018).

Para minimizar os problemas descritos acima, aos responsáveis pelo planejamento e implantação da arborização urbana cabe a obrigação de serem criteriosos na definição das espécies a serem plantadas, observando com cuidado suas características morfológicas e físicas (DALL AQUA; MÜLLER, 2015) para evitar que no futuro a manutenção e o manejo da arborização se tornem excessivamente onerosa. Além disso, a arborização deve ser a mais diversificada possível, preferencialmente priorizando o cultivo de espécies nativas tanto por razões estéticas, como pela necessidade de preservação da biodiversidade vegetal (PIZZIOLO et al., 2014).

Considerando que a implantação da arborização urbana constitui custo para as administrações das cidades (MOREIRA et al., 2018), o seu planejamento adequado pode, simultaneamente, minimizar os danos, maximizar os benefícios e valorizar os investimentos realizados.

Para saber se a arborização urbana de uma cidade foi implantada de forma correta é preciso fazer um diagnóstico da mesma via realização de um inventário (MAMEDE et al., 2014). Em paralelo ao inventário, é necessário fazer um diagnóstico quali-quantitativo da arborização existente, verificando-se as espécies plantadas, o número de indivíduos e analisando-se parâmetros como porte, condições fitossanitárias, locais e condições de plantio, e existência de conflitos das árvores com as estruturas existentes em seu entorno. Por meio do inventário e do diagnóstico quali-quantitativo é possível identificar as necessidades de manejo, localizar riscos relacionados a árvores que necessitam de reparos ou remoção, verificar as características das ruas e elementos urbanos, e indicar novos pontos para plantio (NOWAK, 2008).

Acrelândia foi a primeira cidade planejada do Estado do Acre e foi elevada à categoria de município pela Lei no 1.025/92 de 28 de abril de 1992, a partir do desmembramento de partes dos municípios de Plácido de Castro e Senador Guiomard. A área do município é de $11.575 \mathrm{~km}^{2}$ e ele faz limites com os municípios de Plácido de Castro e Senador Guiomard, os estados do Amazonas e Rondônia e com a Bolívia (ACRE, 2006). A cidade de Acrelândia dista $127 \mathrm{~km}$ da capital do Estado, Rio Branco, pela rodovia BR-364. A população, em número de 13.353 habitantes (IBGE, 2013), é constituída, na sua maioria, por famílias de agricultores que migraram de outras regiões do país, principalmente da Região Sul.

Apesar de ser uma cidade relativamente jovem, uma rápida avaliação de sua arborização urbana revelou que a mesma parece ser extremamente precária, necessitando de melhorias e manejo adequados. Essa parece ser a realidade da arborização em grande parte das cidades acreanas, em geral precárias e denotando falta de planejamento ou planejamento inadequado para acomodar a expansão das cidades, e executadas desconsiderando os preceitos técnicos mais elementares da moderna ciência de arborização urbana (PAIVA et al., 2010). No Acre também se observa, como em outras regiões do país, uma crescente substituição da flora nativa por plantas exóticas na execução da arborização urbana, um procedimento que tende a uniformizar as paisagens em diferentes cidades pelo país e que contribui para a redução da biodiversidade nas áreas urbanas, resultando em uma dissociação do contexto ambiental onde as mesmas estão inseridas (MACHADO et al., 2006). Nesse contexto, o presente estudo se consistiu em uma avaliação da condição qualitativa e quantitativa da arborização urbana da cidade de Acrelândia.. 


\section{MATERIAL E MÉTODOS}

\section{Área de estudo}

O trabalho foi realizado no perímetro urbano da cidade de Acrelândia, capital de município de mesmo. Foram inventariados por meio de um censo (MARANHO; PAULA, 2014) todos os indivíduos arbóreos (com Diâmetro a Altura do Peito-DAP ou Diâmetro à Altura do Colo-DAC igual ou superior a $10 \mathrm{~cm}$ ) encontrados nas 59 ruas da cidade, que somaram uma extensão de $32,52 \mathrm{~km}$ lineares (Figura 1). Acrelândia localiza-se no extremo Nordeste do Acre $\left(10^{\circ} 04^{\prime} 44.27\right.$ "S; $67^{\circ} 03^{\prime 2} 27.04^{\prime \prime W}$ ) e está a $130 \mathrm{~km}$ da cidade de Rio Branco, capital do estado.
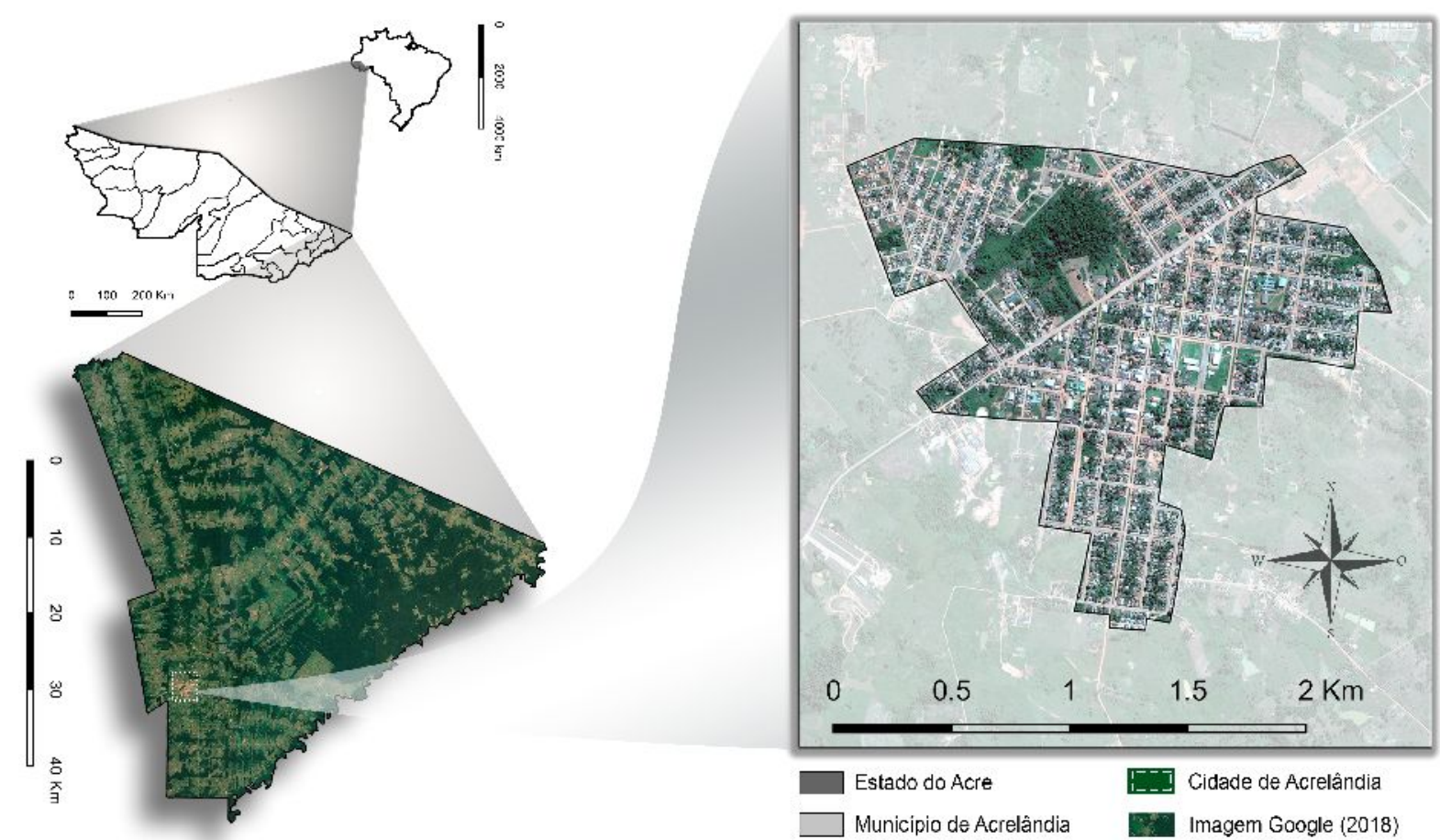

FIGURA 1 - Localização do município de Acrelândia no estado do Acre.

Fonte da imagem: Google Earth (2018).

Edição da Imagem: Ivan Oliveira e Daniel Papa.

\section{Variáveis quantitativas avaliadas}

Altura da primeira bifurcação, medida com o auxílio de uma trena; Altura total medida com trena até os $2 \mathrm{~m}$, acima disso ela foi estimada com uma régua graduada, Diâmetro à Altura do Peito (DAP) ou Diâmetro a Altura do Colo (DAC), medido com trena diamétrica.

\section{Variáveis qualitativas avaliadas}

Identificação (nome popular, científico e família botânica), origem (nativa para espécies oriundas da região Amazônica, e exótica - para espécies introduzidas de outras regiões e biomas brasileiros, incluindo as introduzidas de outros países) e localização do plantio (canteiro, calçada, praça). A pavimentação no local do plantio (pavimentado, não pavimentado) e o conflito com a fiação aérea e a iluminação pública seguiram o procedimento adotado por Moreira et al. (2018). Foram avaliados ainda o tipo de poda (sem poda, de condução, topiária), intensidade de poda (sem poda, leve, pesada e drástica), necessidade de poda, condição do tronco (sem ENCICLOPÉDIA BIOSFERA, Centro Científico Conhecer - Goiânia, v. 15 n.28; p. 72 
injúrias, ocado, vandalismo), condição do colo da planta (não pavimentado, pavimentado, insuficiente, suficiente), sistema radicular aparente ou não aparente e os danos que o mesmo causava (sem danos, danos em calçadas, guias de ruas e muros). A Condição fitossanitária das árvores avaliadas (boa: árvores vigorosas; regular: sem injúrias significativas; ruim: injúrias significativas; mortas), seguiu a proposição de Boeni e Silveira (2011).

\section{Identificação das espécies}

As identificações preliminares das espécies no campo foram feitas com o auxílio de um parataxonomista. Espécies não identificadas no campo foram identificadas mediante consulta adicional ao acervo do Herbário do Parque Zoobotânico da Universidade Federal do Acre (UFAC), em Rio Branco, Acre e acervos online do Missouri Botanical Garden (http://www.tropicos.org/Name) e do Jardim Botânico de Nova Yorque (http://sweetgum.nybg.org/science/vh/). A nomenclatura atualizada dos táxons foi verificada, seguindo os procedimentos adotados por Silva et al. (2018), no sítio eletrônico The Plant List (http://www.theplantlist.org).

\section{Coleta e análise dos dados}

Os dados do levantamento quali-quantitativo e a identificação preliminar das espécies foram anotados em uma planilha de levantamento de dados e posteriormente tabulados e processado no programa Microsoft Excel versão 2007 (SANTOS et al., 2018). A frequência relativa de cada espécie foi calculada pela razão entre o número de indivíduos da espécie e o número total de indivíduos levantado na referida cidade, multiplicado por 100 (SILVA et al., 2018).

\section{RESULTADOS E DISCUSSÃO}

\section{Análise quantitativa da arborização}

O levantamento censitário realizado resultou na contabilização de 375 árvores, distribuídas em 25 espécies e 15 famílias botânicas (QUADRO 1).

QUADRO 1 - Lista de espécies arbóreas encontradas nas ruas e calçadas da cidade de Acrelândia, Acre.

\begin{tabular}{|c|c|c|c|c|c|c|}
\hline № & Nome vulgar & Espécies & Família/Subfamília & Origem $^{1}$ & $\mathrm{~N}^{2}$ & $\mathrm{~F}^{3}$ \\
\hline 1 & Abiu massa & $\begin{array}{l}\text { Pouteria caimito (Ruiz \& Pav.) } \\
\text { Radlk. }\end{array}$ & Sapotaceae & $\mathrm{n}$ & 1 & 0,27 \\
\hline 2 & Acácia & Acacia sp. & Fabaceae & e & 2 & 0,53 \\
\hline 3 & $\begin{array}{l}\text { Açaí-de- } \\
\text { touceira }\end{array}$ & Euterpe oleraceae Mart. & Arecaceae & e & 3 & 0,80 \\
\hline 4 & Azeitona & Eugenia sp. & Myrtaceae & e & 1 & 0,27 \\
\hline 5 & Brinco de ouro & Lophanthera lactescens Ducke & Malphiguiaceae & $\mathrm{n}$ & 3 & 0,80 \\
\hline 6 & $\begin{array}{l}\text { Bordão-de- } \\
\text { velho }\end{array}$ & Samanea saman (Jacq.) Merr. & Mimosaceae & $\mathrm{n}$ & 1 & 0,27 \\
\hline 7 & Carambola & Averrhoa carambola L. & Oxalidaceae & e & 4 & 1,07 \\
\hline 8 & Castanhola & Terminalia catappa L. & Combretaceae & e & 5 & 1,33 \\
\hline 9 & Caxinguba & Ficus maxima Mill. & Moraceae & $\mathrm{n}$ & 1 & 0,27 \\
\hline 10 & Chapéu-chinês & Holmskioldia sanguinea Retz. & Verbenaceae & e & 1 & 0,27 \\
\hline 11 & $\begin{array}{l}\text { Cumaru de } \\
\text { Cheiro }\end{array}$ & Dipteryx odorata (Aubl.) Willd. & Fabaceae & $\mathrm{n}$ & 2 & 0,53 \\
\hline $\begin{array}{l}12 \\
13\end{array}$ & $\begin{array}{l}\text { Benjamin } \\
\text { Goiabeira }\end{array}$ & $\begin{array}{l}\text { Ficus benjamina L. } \\
\text { Psidium quaiava L }\end{array}$ & $\begin{array}{l}\text { Moraceae } \\
\text { Myrtaceae }\end{array}$ & $\begin{array}{l}\mathrm{e} \\
\mathrm{e}\end{array}$ & $\begin{array}{c}230 \\
1\end{array}$ & $\begin{array}{c}61,33 \\
0,27\end{array}$ \\
\hline
\end{tabular}




\begin{tabular}{|c|c|c|c|c|c|c|}
\hline 14 & Inga & | Inga sp. & Fabaceae & $\mathrm{n}$ & 1 & 0,27 \\
\hline 15 & Ipê amarelo & $\begin{array}{l}\text { Handroanthus serratifolius (Vahl) } \\
\text { S.O.Grose }\end{array}$ & Bignoniaceae & $\mathrm{n}$ & 1 & 0,27 \\
\hline 16 & Ipê-roxo & $\begin{array}{l}\text { Handroanthus impetiginosus (Mart. } \\
\text { ex DC.) Mattos }\end{array}$ & Bignoniaceae & $\mathrm{n}$ & 1 & 0,27 \\
\hline 17 & Jambo & $\begin{array}{l}\text { Syzygium malaccense (L.) Merr. \& } \\
\text { L.M. Perry }\end{array}$ & Myrtaceae & $\mathrm{e}$ & 22 & 5,87 \\
\hline 18 & Leucena & Leucaena sp. & Fabaceae & e & 4 & 1,07 \\
\hline 19 & Limão galego & $\begin{array}{l}\text { Citrus aurantiifolia (Christm.) } \\
\text { Swingle }\end{array}$ & Rutacea & e & 1 & 0,27 \\
\hline $\begin{array}{l}20 \\
21\end{array}$ & $\begin{array}{l}\text { Mangueira } \\
\text { Oiti }\end{array}$ & $\begin{array}{l}\text { Mangifera indica } \mathrm{L} \text {. } \\
\text { Licania tomentosa (Benth.) Fritsch }\end{array}$ & $\begin{array}{l}\text { Anacardiaceae } \\
\text { Chrysobalanaceae }\end{array}$ & $\begin{array}{l}\mathrm{e} \\
\mathrm{n}\end{array}$ & $\begin{array}{c}8 \\
18\end{array}$ & $\begin{array}{l}2,13 \\
4,80\end{array}$ \\
\hline 22 & $\begin{array}{l}\text { Palmeiraimperi } \\
\text { al }\end{array}$ & $\begin{array}{l}\text { Roystonea oleracea (Jacq.) O.F. } \\
\text { Cook }\end{array}$ & Arecaceae & e & 8 & 2,13 \\
\hline $\begin{array}{l}23 \\
24\end{array}$ & $\begin{array}{l}\text { Pinheiro } \\
\text { Sapoti }\end{array}$ & $\begin{array}{l}\text { Thuja occidentalis L. } \\
\text { Manilkara zapota (L.) P.Royen }\end{array}$ & $\begin{array}{l}\text { Cupressaceae } \\
\text { Sapotaceae }\end{array}$ & $\begin{array}{l}\mathrm{e} \\
\mathrm{e}\end{array}$ & $\begin{array}{l}3 \\
1\end{array}$ & $\begin{array}{l}0,80 \\
0,27\end{array}$ \\
\hline 25 & Sibipiruna & $\begin{array}{l}\text { Caesalpinia pluviosa var. } \\
\text { peltophoroides (Benth.) G.P.Lewis }\end{array}$ & Fabaceae & e & 52 & 13,87 \\
\hline & & & & & 375 & $100 \%$ \\
\hline
\end{tabular}

${ }^{1}$ n: nativa, e: exótica; ${ }^{2}$ Número de indivíduos; ${ }^{3}$ Frequência relativa (\%).

Observou-se uma alta frequência de indivíduos em poucas espécies, especialmente Ficus benjamina $(61,3 \%)$ e Caesalpinia pluviosa var. peltophoroides (13,8\%). As dez espécies com maior frequência representam 94,4\% da população. De acordo com as recomendações de Grey e Deneke (1978), quando um bom planejamento de arborização urbana é feito, cada espécie não deve ultrapassar 10$15 \%$ do total de indivíduos da população arbórea. Silva Filho e Bortoleto (2005) comentam que a diversidade de espécies presentes na arborização urbana das cidades do Brasil é geralmente baixa, prevalecendo, na maioria dos casos, uma situação de homogeneidade, ou seja, um grande número de indivíduos distribuídos em poucas espécies. Nesse sentido, a cidade de Acrelândia não atende a este aspecto, pois duas espécies representaram mais de $75 \%$ do total de indivíduos cultivados. Ficus benjamina é reconhecida por ser prejudicial à estrutura urbana, especialmente calçadas, muros e redes aéreas (SANTANA; SANTOS, 1999). Outro aspecto prejudicial dessa espécie é a produção excessiva de biomassa (folhas) que pode entupir galerias pluviais e prejudicar a limpeza pública (MARTINS-NETO et al., 2016).

\section{Quantidade de árvores por quilômetro de calçada}

A quantidade de árvores $/ \mathrm{km}$ de calçada encontrada em Acrelândia foi de 5,75, muito inferior ao recomendado pela Sociedade Brasileira de Arborização Urbana, que recomenda como número ideal pelo menos 100 indivíduos por km linear de calçada (PAIVA et al., 2010). Nesse sentido, Acrelândia assemelha-se à cidade de Rio Branco-AC (com 4,57 indivíduos $/ \mathrm{km}$ de calçada), que segundo Paiva et al. (2010) é um dos menores índices do Brasil.

\section{Porte das plantas}

$\mathrm{Na}$ altura total das árvores verificou-se que 179 indivíduos $(47,7 \%)$ variaram de 5,1 a 10m, $151(40,2 \%)$ apresentaram altura inferior a $5 \mathrm{~m}, 32$ (8,5\%) apresentaram altura entre 10,1 e $15 \mathrm{~m}, 8(2,1 \%)$, apresentavam altura entre 15,1 e $20 \mathrm{~m}$, e $5(1,3 \%)$ com altura entre 20,1 e $25 \mathrm{~m}$. O fato de $87,9 \%$ dos indivíduos estarem representados na primeira e segunda classe de altura indica que a maioria ENCICLOPÉDIA BIOSFERA, Centro Científico Conhecer - Goiânia, v.15 n.28; p. 74 2018 
das árvores plantadas possivelmente ainda não atingiu pleno desenvolvimento. Deve-se levar em conta o fato de Acrelândia ser uma cidade com pouco mais de 25 anos de fundação.

\section{Altura da primeira bifurcação}

Das árvores avaliadas, 97,1\% apresentavam a primeira bifurcação na altura de dois metros, considerada ideal para facilitar a passagem de pedestres. Uma correta condução do crescimento das plantas (poda) poderá evitar problemas futuros. Segundo Gonçalves e Paiva (2006), a altura da primeira bifurcação deve ser de pelo menos $1,80 \mathrm{~m}$ quando as mudas forem levadas do viveiro para o plantio definitivo para evitar transtornos aos pedestres e veículos de pequeno porte que transitarem sob a área de influência da copa.

\section{Diâmetros das plantas (DAP)}

Constatou-se que 61,6 \% dos indivíduos apresentaram diâmetro inferior a 30 $\mathrm{cm}$, indicando que as árvores plantadas nas vias públicas da cidade ainda estão em fase de crescimento. Árvores com DAP menor que $10 \mathrm{~cm}$ foram 5,8\% (22 indivíduos), com DAP entre 10 e $20 \mathrm{~cm}$ corresponderam a $27,2 \%$ (102 indivíduos), entre 20 e $30 \mathrm{~cm}$ foram $28 \%$ da população, $31,6 \%$ estavam entre 30 e $40 \mathrm{~cm}(115$ indivíduos), entre 40 e $50 \mathrm{~cm}$ foram $6,4 \%$ (24 indivíduos), entre 50 e $60 \mathrm{~cm}$ representaram 1,6\% (6 indivíduos) e maiores que $70 \mathrm{~cm}$ corresponderam a 0,2\% (um indivíduo).

\section{Análise qualitativa da arborização}

\section{Origem das espécies cultivadas}

Das espécies identificadas, 92,8\% são exóticas e apenas $7,2 \%$ são nativas, indicando que não houve escolha adequada das espécies plantadas, especialmente se for considerada a enorme biodiversidade existente nas florestas que cerca a cidade.

\section{Locais de cultivo}

Em relação ao local de cultivo das plantas, $84,5 \%$ encontram-se nas calçadas. Outras $12,8 \%$ das plantas são cultivadas em canteiros e $2,6 \%$ nas praças. Das árvores presentes nas calçadas a frequência de plantio das espécies $F$. benjamina e Caesalpinia pluviosa var. peltophoroides foi de $84,5 \%$. A escolha dessas espécies possivelmente se deu pelo fornecimento de sombra, já que possuem copa densa, entretanto, no futuro os danos em calçadas, muros adjacentes e guias das ruas serão elevados, especialmente aqueles causados por $F$. benjamina, reconhecida como inadequada para uso na arborização urbana em razão de do seu sistema radicular que cresce superficialmente e provoca estes tipos de danos (SANTOS et al., 2015).

\section{Pavimentação do local de cultivo}

Quanto à pavimentação no local do cultivo a maioria $(53,3 \%)$ encontra-se em local sem pavimentação, pois Acrelândia é uma cidade relativamente nova e grande parte das calçadas ainda não está pavimentada. 


\section{Plantas afetando a fiação e a iluminação pública}

Das plantas avaliadas, apenas $3,2 \%$ estavam interferindo com a fiação elétrica e telefônica e $0,5 \%$ a iluminação pública. Estes baixos índices devem-se ao fato de a fiação elétrica estar localizada nos canteiros centrais das ruas, que abrigavam apenas $12,8 \%$ das árvores cultivadas na cidade. Segundo CEMIG (2001) o plantio de árvores nas cidades deve ser feito de forma compatível com a fiação aérea, devendo-se utilizar, quando o plantio for feito sob a fiação elétrica, espécies arbóreas de pequeno porte.

\section{Podas}

\section{Tipo de poda realizada}

Das plantas avaliadas, $45,3 \%$ apresentavam poda de condução e $35,7 \%$ não apresentavam sinais de poda. Outras $6,9 \%$ apresentavam sinais de poda topiária e $11,4 \%$ poda de condução e topiária. Costa e Higuchi (1999) constataram na cidade de Manaus, que 15\% das árvores apresentaram copa boa, 65\% regular e 19\% ruim.

\section{Intensidade de Poda}

A avaliação mostrou que $35,7 \%$ da arborização não apresentavam sinais de poda, possivelmente indicando ausência de conflitos com a estrutura urbana adjacentee conflitos com a rede elétrica. Dos indivíduos avaliados $64,2 \%$ sofreram algum tipo de poda, dos quais $49,6 \%$ correspondiam à poda leve. $O$ percentual de poda drástica observado na arborização em Acrelândia foi baixo (8,5\%). Paula e Melo (2010), em diagnóstico da arborização de Planalto-SP, relacionaram que as espécies que apresentaram fitossanidade ruim foram árvores de grande porte que, possivelmente, foram submetidas a podas drásticas.

\section{Necessidade de poda}

A maioria das árvores $(63,2 \%)$ necessitava de poda de adequação, indicando que estavam em fase de crescimento. Em Mangueirinha-PR, $51,8 \%$ das plantas avaliadas não precisava de poda (SCHALLENBERGER et al., 2013).

\section{Condições do tronco das plantas}

Das plantas avaliadas $80,5 \%$ não apresentavam injúrias e 18,9\% apresentavam sinais de vandalismo.

\section{Condições do colo das plantas}

Em $46,1 \%$ dos casos o colo das plantas era pavimentado e em apenas $0,5 \%$ dos mesmos o espaço de colo era adequado para o desenvolvimento das plantas até a fase adulta. Esta constatação é um claro indicativo de que no futuro será necessário adequar o espaço de colo para as plantas para evitar casos de mortalidade e crescimento atrofiado de alguns indivíduos.

\section{Condição do sistema radicular}

O resultado da avaliação mostrou que $68 \%$ das plantas apresentavam raízes expostas e $32 \%$ não expostas. Esse resultado possivelmente foi influenciado pela ocorrência de um grande número de indivíduos com sistema radicular superficial, como são os casos de F. benjamina e Lophantera lactescens. Como mais de $80 \%$ das plantas era cultivada em calçadas, existe a expectativa futura de que, na medida 
em que as plantas atinjam a fase adulta, os danos causados em calçadas aumentem consideravelmente.

\section{Danos causados pelo sistema radicular}

Foi observado que $42,7 \%$ das plantas causavam danos em calçada, 1,6\% em muros, $8,2 \%$ em guias de ruas e $47,7 \%$ não causavam danos. $O$ grande percentual de danos em calçadas e muros decorre do cultivo de um grande número de indivíduos das espécies $F$. benjamina e Lophantera lactescens.

\section{Fitossanidade}

A maioria das árvores avaliadas (96\%) foi classifica como boa, 0,8\% como regular e 1,6\% como ruim. A taxa de mortalidade calculada foi de $2,1 \%$, em sua maioria decorrente da ação dos moradores, que derrubaram as árvores em razão dos danos que elas causaram em suas residências.

\section{CONCLUSÕES;}

- Os resultados obtidos permitem concluir que não houve planejamento e obediência a preceitos técnicos durante a implantação da urbanização realizada em Acrelândia, com destaque para o uso excessivo de espécies exóticas e de plantas com grande potencial de causar prejuízos às estruturas urbanas; percentual de espécies exóticas indica que a arborização da cidade não foi planejada e desconsiderou o uso de espécies nativas, abundantes nas florestas existentes próximo da cidade;

- A arborização avaliada é recente e apesar das condições gerais de desenvolvimento e conservação dos indivíduos avaliados ser satisfatória, verificou-se a necessidade de ajustes no que se refere ao espaço do colo das plantas e realização de podas de adequação na copa da maioria das árvores;

- De uma maneira geral a arborização urbana em Acrelândia não se diferencia daquela observada em muitas cidades do Brasil, nas quais verifica-se o plantio de numerosos indivíduos de poucas espécies, conferindo um caráter homogêneo e monótono à arborização.

\section{REFERÊNCIAS}

ACRE. Governo do Estado do Acre. Zoneamento Ecológico-Econômico do Acre, Fase II: documento síntese-escala 1:250.000. Rio Branco, Acre: Sema, 2006. 356p.

BOENI, B.O.; SILVEIRA, D. Diagnóstico da arborização urbana em bairros do município de Porto Alegre, RS, Brasil. Revista da Sociedade Brasileira de Arborização Urbana, v.6, n.3, p.189-206, 2011.

CEMIG - COMPANHIA ENERGÉTICA DE MINAS GERAIS. Manual de arborização. Belo Horizonte: Superintendência do Meio Ambiente/CEMIG, 2001. 40p.

COSTA, L.A.; HIGUCHI, N. Arborização de ruas de Manaus: avaliação qualitativa e quantitativa. Revista Árvore, v.23, n.2, p.223-232, 1999. 
CRISPIM, D.L.; DA SILVA, M.A.; CHAVES, A.C.G.; ALMEIDA, R.R.P.; FREITAS, A.J.F. Diagnóstico da arborização urbana do centro da cidade de Pombal-PB. Revista Verde, v.9, n.1, p.191-196, 2014. Disponível em: <http://www.gvaa.com.br/revista/index.php/RVADS/article/view/2707>.

DALL AQUA, M.; MÜLLER, N.T.G. Diagnóstico da arborização urbana de duas vias na cidade de Santa Rosa - RS. Revista da Sociedade Brasileira de Arborização Urbana, v.9, n.3, p.141-155, 2014. Disponível em: <http://www.revsbau.esalq.usp.br/artigos_cientificos/artigo223sn-publicacao.pdf >.

FARIA, D.C.; DUARTE, J.M.A.; PINTO, D.M; ALMEIDA, F.S. Arborização urbana no município de Três Rios-Rj: Espécies utilizadas e a percepção de seus benefícios pela população. Revista brasileira de arborização urbana, v.8, n.2, p.58-67, 2013.

GOMES, E.M.C.; RODRIGUES, D.M.S.; SANTOS, J.T.; BARBORSA, E.J. Análise quali-quantitativa de uma praça urbana no norte do Brasil. Nativa, v.4, n.3, p.179186 , 2016. Disponível em: <http://periodicoscientificos.ufmt.br/ojs/index.php/nativa/article/view/3180>.

GONÇALVES, W.; PAIVA, H.N. Silvicultura Urbana: Implantação e manejo. Viçosa, MG: Aprenda Fácil, v. 4, 201 p. 2006.

GREY, G.W.; DENEKE, F.J. Urban forestry. New York: John Wiley, 1978.

IBGE. Instituto Brasileiro de Geografia e Estadística - Sinopse do senso Demográfico. 2013. Disponível em: <http://www.ibge.gov.br/home/estatistica/populacao/estimativa2013/estimativa_dou.s $\mathrm{htm}>$.

LACERDA, M.A.; SOARES, F.S.; COSTA, J.P.M.; MEDEIROS, R.S.; MEDEIROS, E.N.; CARVALHO, J.A.; SILVA, Z.L. Levantamento florístico de arborização urbana nas principais vias públicas do município de Boa Ventura - PB. Revista Brasileira de Gestão Ambiental, v.7, n.4, p.12-16, 2014.

MACHADO, R.R.M.; MEUNIER, I.M.J.; SIVA, J.A.A.; CASTRO, A.A.J.F. Árvores nativas para a arborização de Teresina, Piauí. Revista da Sociedade Brasileira de Arborização Urbana, Piracicaba, v.1, n.1. 2006. Disponível em: $<$ https://www.researchgate.net/profile/lsabelle_Meunier4/publication/237113394_AR VORES_NATIVAS_PARA_A_ARBORIZACAO_DE_TERESINA_PIAUI/links/5400da3 80cf23d9765a48aba/ARVORES-NATIVAS-PARA-A-ARBORIZACAO-DE-

TERESINA-PIAUI.pdf?origin=publication_detail>.

MAMEDE, J.S.S.; SOUZA, F.F.; SANTOS, A.F.A.; DUTRA, F.M.C.; RONDON NETO, R.M. Levantamento quali-quantitativo de espécies arbóreas e arbustivas na arborização urbana do município de Paranaíta, Mato Grosso. Biodiversidade, v.13, n.2, p.56-63, $2014 . \quad$ Disponível em: <http://periodicoscientificos.ufmt.br/ojs/index.php/biodiversidade/article/view/1956>. 
MARANHO, A.S.; PAULA. S.R.P. Diversidade em uma área verde urbana: avaliação qualitativa da arborização do campus da Universidade Federal do Acre, Brasil. Revista Agro@mbiente On-line, v.8, n.3, p.404-415, 2014. Disponível em: $<$ https://revista.ufrr.br/agroambiente/article/view/1868>.

MARTINS NETO, F.F.; CALADO, P.I.N.; BAILÃO, R.O.; LIMA, E.C.; MIRANDA, Y.C.; BALESTRI, E.L.; SOUZA, D.C.; CAXAMBU, M.G. Espécies exóticas invasoras na área urbana de Tuneiras do Oeste, Paraná. SaBios: Rev. Saúde e Biol., v.11, n.2, p.33-41, $2016 . \quad$ Disponível em: $<$ http://revista2.grupointegrado.br/revista/index.php/sabios2/article/download/2036/87 $9>$.

NOWAK, D.J. Assessing urban forest structure: Summary and conclusions. Arboriculture and Urban Forestry, v.34, n.6, p.391-392, 2008. Disponível em: $<$ https://www.nrs.fs.fed.us/pubs/jrnl/2008/nrs_2008_nowak_002.pdf>.

OLIVEIRA, L.M.; SANTOS, A.F.; SOUZA, P.A.; ALVES, K.C.C.L.F.; GIONDO, M. Diagnóstico da arborização nas calçadas de Gurupi, TO. Revista da Sociedade Brasileira de Arborização Urbana, v.12, n.1, p.105-121, 2017. Disponível em: $<$ http://www.revsbau.esalq.usp.br/teste/ojs-

2.3.7/index.php/REVSBAU/article/view/641>.

OLIVEIRA, A.S.; SANCHES, L.; MUSIS, C.R. Benefícios da arborização em praças urbanas - o caso de Cuiabá/MT. Rev. Elet. em Gestão, Educação e Tecnologia Ambiental, v.9, n.9, p.1900-1915, 2013. Disponível em: $<$ https://periodicos.ufsm.br/reget/article/viewFile/7695/pdf>.

PAIVA, A.V.; LIMA, A.B.M.; CARVALHO, A.L.; MIRANDA JUNIOR, A.; GOMES, A., et al. Inventário e diagnóstico da arborização urbana viária de Rio Branco, AC. Revista da Sociedade Brasileira de Arborização Urbana, v.5, n.1, p.144-159, 2010. Disponível em: <http://www.revsbau.esalq.usp.br/ artigos_cientificos/artigo86publicacao.pdf>. Acesso em: 28 maio 2014.

PIZZIOLO, B.V.; TOSTES, R.; SILVA, K.; ARRUDA, V.M. Arboriação urbana: Percepção ambiental dos moradores dos bairros Bom Pastor e Centro da cidade de Ubá/MG. Reget, v.18, n.3, p.1162-1169, 2014. Disponível em: $<$ http://dx.doi.org/10.5902/2236117013863>.

SANTANA, J.R.F.; SANTOS, G.M.M. Arborização do campus da UEFS: exemplo a ser seguido ou um grande equívoco? Sitientibus, n.20, p.103-107, 1999. Disponível em: <http://www2.uefs.br/sitientibus/pdf/20/arborizacao_do_campus_da_uefs.pdf>.

SANTOS, R.C.; BESSEGATTO, D.; ANTUNES, L.; MALENGO, F.M.R. Análise quali-quantitativa da arborização urbana do centro da cidade de SananduvaRS.Revista de gest. sust. ambient., v.7, n.2, p.143-158, abr./jun. 2018. Disponível em: DOI:10.19177/rgsa.v7e22018143-158 
SANTOS, C.Z.A.; FERREIRA, R.A.; SANTOS, L.R.; SANTOS, L.I.; GOMES, S.H.; GRAÇA, D.A.S. Análise qualitativa da arborização urbana de 25 vias públicas da cidade de Aracaju - SE. Ciência Florestal, v. 25, n. 3, p.751-763, 2015. Disponível em: <http://dx.doi.org/10.5902/1980509819678>.

SANTOS, A.F.; JOSE, A.C.; SANTOS, P.A. Fitossociologia e diversidade de espécies arbóreas das praças centrais do município de Gurupi-TO. Revista da

Sociedade Brasileira de Arborização Urbana, v. 8, n. 4, p.36-46, 2013.

Disponível

em:

$<$

http://www.revsbau.esalq.usp.br/artigos_cientificos/artigo71snpublicacao.pdf>.

SCHALLENBERGER, L.S.; MACHADO, G.O. Inventário da arborização na região central do município de Mangueirinha-PR. Revista da Sociedade Brasileira de Arborização Urbana, v.8, n.1, p.54-64, 2013. Disponível em: <http://www.revsbau.esalq.usp.br/artigos_cientificos/artigo233-publicacao.pdf>.

SILVA, L.S.; OLIVEIRA, Y.R.; SILVA, P.H.; PIMENTEL, R.M.M.; ABREU, M.C. Inventário das plantas arbustivo-arbóreas utilizadas na arborização urbana em praças públicas. Journal of Environmental Analysis and Progress, v.3, n.2, p.241-249, $2018 . \quad$ Disponível em: <http://ead.codai.ufrpe.br/index.php/JEAP/article/view/1834/482482534>.

SILVA FILHO, D.F.; BORTOLETO, S. Uso de indicadores de diversidade na definição de plano de manejo da arborização viária de Águas de São Pedro - SP. Revista Árvore, v.29, n.6, p.973-982, 2005. Disponível em: $<$ http://www.scielo.br/pdf/rarv/v29n6/a17v29n6.pdf>.

ZAMPRONI, K.; BIONDI, D.; MARIA, T.R.B.C; LOUVEIRA, F.A. Diagnóstico qualiquantitativo da arborização viária de Bonito, Mato Grosso do Sul. Floresta, v.48, n.2, p.235-244, 2018. Disponível em: DOI: 10.5380/rf.v48 i2.55531. 